\title{
Pubis growth study: Applicability in sexual and age diagnostic
}

Unitat d'Antropologia, Departament de Biologia Animal, Vegetal i Ecologia, Universitat Autònoma de Barcelona, 08193 Bellaterra (Barcelona), Spain Received 12 December 2005; received in revised form 28 July 2006; accepted 22 February 2007

\section{Introduction}

To develop reliable methods of sexual determination and age estimation of sub-adult individuals, a profound knowledge of growth is necessary. On the other hand, it is important to have a growth record for all the different skeletal elements, which can be used as a reference in the study of osteological remains. Hence taking into account that the acetabular point is the anatomical point of Ref. [1] to develop innominate growth studies from birth to old age, two cross-sectional studies using documented series were developed. These studies were based on two pelvic elements, the ischium [2] and the ililum [3]. Now, with the intention of completing innominate growth studies and the pubis and the ischiopubic area being important for age and sex determination in both the adult [4-10] and sub-adult [1115], the main objective of the present study is to furnish data on the ischiopubic area. Therefore, certain metric variables of the pubis and the relationship between the pubis and ischium were

\footnotetext{
* Corresponding author. Tel.: +34 6611424 08; fax: +34 935811321 .

E-mail address: Carme.Rissech@uab.es (C. Rissech).
}

analyzed from the anatomical definition of the acetabular point. Thus, it is possible to define the usefulness of such variables in the determination of sex and age at death.

\section{Materials and methods}

The material used consists of 327 innominates, from which the pubis element was measured (Figs. 1 and 2), originating from four documented skeletal series: the St. Bride collection from London, Esqueletos Identificados from the University of Coimbra, the Lisbon collection from the Museum Bocage of Lisbon and the skeletal series of the Universitat Autònoma de Barcelona (UAB). The individuals used in this study were buried between the 18th and 20th centuries. Details regarding age and sex appear in Table 1. Information about these four European collections and their pattern of growth and development can be found in several papers of different authors such as Black and Sheuer [16-18], Safont et al. [19], Rissech et al. [1,2], Rissech and Malgosa [3], Rocha [20] and Cardoso [21].

The variables selected are the classical pubis length and three new variables, which describe the pubis acetabular surface of the immature acetabulum, and the classical ischiopubic index. The measurements used are:

- Pubis length. Distance between the acetabular point and the central point of the upper rim of the pubis symphysis [6] (Fig. 1, 1).

- Ischiopubic index. Percentage ratio between pubis length and ischium length [5]. The ischium length measurements for this variable were 

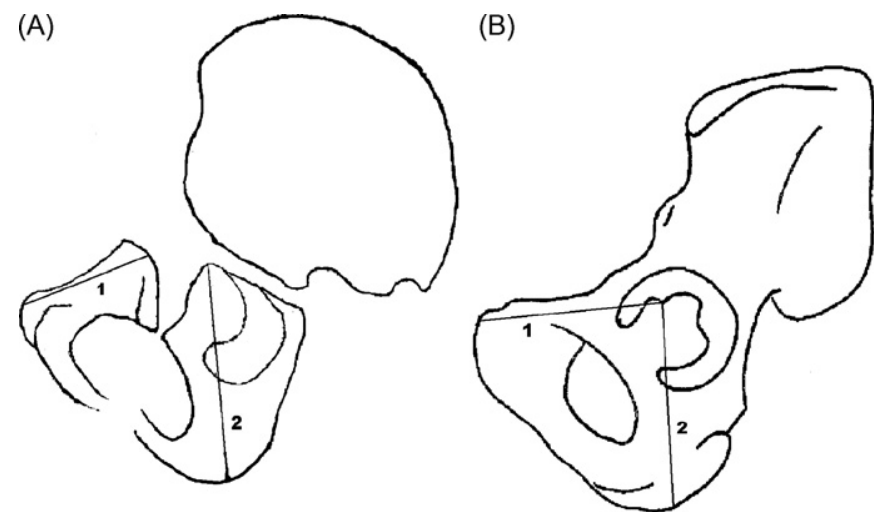

Fig. 1. Non-fused (A) and fused coxal bone (B): pubis length (1) and ischium length (2).

obtained from our previous study [2].

- Vertical diameter of the pubis acetabular area. Distance between the superior and inferior borders of the pubis acetabular area. The measurement follows the axis of the superior pubic ramus (Fig. 2, 1).

- Horizontal diameter of the pubis acetabular area. Distance between the acetabular point and the external border of the pubis acetabular area. This measurement is perpendicular to the vertical diameter of the pubis acetabular area (Fig. 2, 2).

- Pubis acetabular index. The percentage ratio between the horizontal and vertical diameter of pubis acetabular area.

All the variables were measured in all individuals of the series. However, the last three measurements describing the pubic acetabular surface on the immature acetabulum were measured only on the young non-fused pubis. In spite of this, these acetabular measurements have been applied to the UAB collection which consists of adult individuals - with the aim of testing the applicability of these measurements in adult innominate bones. This can be done due to the relation of adult and sub-adult anatomical points observed by Rissech et al. [1].

To locate the acetabular point, the morphological descriptions of Rissech et al. [1] have been taken into account. In all the measurements, we checked to ensure that the differences between right and left bones are negligible; in consequence, only the left side was used. If the left innominate was damaged or pathologic, the right innominate was used.

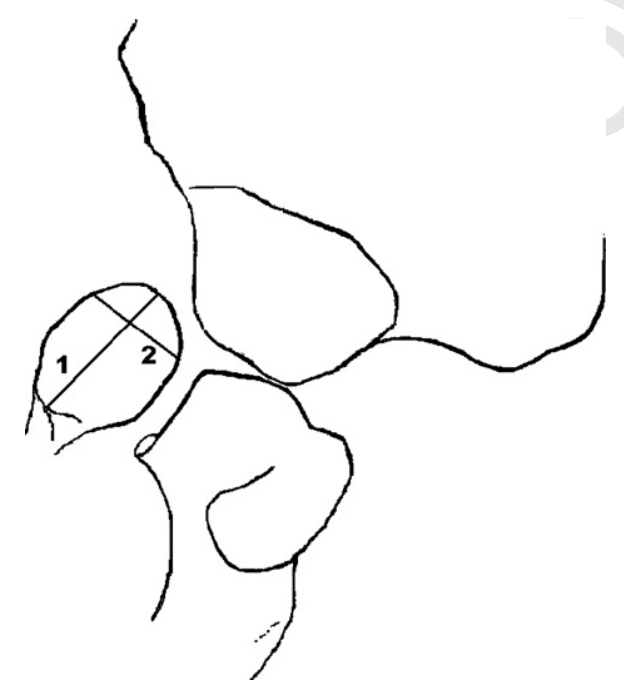

Fig. 2. Non-fused coxal bone: vertical diameter (1) and horizontal diameter (2) of pubic acetabular surface.
Table 1

Distribution of specimens by sex, age and population

\begin{tabular}{|c|c|c|c|c|c|c|c|c|c|c|}
\hline \multirow[t]{2}{*}{ Age } & \multicolumn{2}{|c|}{$\mathrm{Sb}$} & \multicolumn{2}{|l|}{ Co } & \multicolumn{2}{|c|}{$\mathrm{Lb}$} & \multicolumn{2}{|l|}{ Gr } & \multicolumn{2}{|c|}{ Total } \\
\hline & $\mathrm{M}$ & $\mathrm{F}$ & M & $\mathrm{F}$ & M & $\mathrm{F}$ & M & $\mathrm{F}$ & $\mathrm{M}$ & $\mathrm{F}$ \\
\hline $0-4$ & 3 & 1 & & & 11 & 5 & & & 14 & 6 \\
\hline $5-9$ & 5 & & 2 & 4 & 4 & 4 & & & 11 & 8 \\
\hline $10-14$ & 1 & 1 & 2 & 11 & 2 & 4 & & & 5 & 16 \\
\hline $15-19$ & 1 & 2 & 11 & 13 & 6 & 6 & & & 18 & 21 \\
\hline $20-25$ & 5 & 4 & 11 & 8 & 5 & 12 & & & 21 & 24 \\
\hline $26-30$ & 2 & 3 & 6 & 4 & 5 & 6 & & & 13 & 13 \\
\hline $31-35$ & 2 & 3 & 3 & 1 & 5 & 6 & 2 & & 12 & 10 \\
\hline $36-45$ & 5 & 7 & 9 & 6 & 9 & 6 & 1 & & 24 & 19 \\
\hline $46-55$ & 3 & 5 & 5 & 5 & 9 & 7 & 3 & & 20 & 17 \\
\hline $56-65$ & 11 & 4 & & & & & 5 & 1 & 16 & 5 \\
\hline $66-75$ & 3 & 5 & & & & & 3 & 4 & 6 & 9 \\
\hline \multirow[t]{2}{*}{$76-97$} & 1 & 3 & & & & & 5 & 10 & 6 & 13 \\
\hline & 42 & 38 & 49 & 52 & 56 & 56 & 19 & 5 & 166 & 161 \\
\hline
\end{tabular}

Sb: St. Bride collection, London (18th to 19th century); Co: collection of Esqueletos Identificados of Coimbra (19th to 20th century); Lb: Lisbon collection (19th to 20th century); Gr: collection of the Universitat Autònoma de Barcelona. Males are indicated by $\mathrm{M}$ and females are indicated by $\mathrm{F}$.

\subsection{Statistical analysis}

As the documented series were of different sizes and unequal composition in age and sex, and following current methodological practice, each series was divided using 5-year intervals. However, the intervals used for adults were longer (20 years) because growth in these individuals must have finished.

First, the homogeneity of the series was analyzed. In adults the ANOVA test was applied. In sub-adults a graphic method, "lowess" was applied, due to the different composition of the samples in the several age groups and the derived differences due to growth (see Rissech et al. [2] and Rissech and Malgosa [3]).

Second, a first sexual dimorphism approximation was analyzed in each age group by Studend's $t$ or Mann-Whitney's $U$. Because of the lack of homogeneity in younger groups, the different rhythm of growth within and among groups, and the small size of the sample the results of this analysis have to be used carefully.

Third, the growth behaviour of each of the six variables was analyzed by polynomial regression until the fifth degree because it can be assumed that the dynamics of growth can be described by an incremental continuous function $[13,22]$. The significance of the functions and coefficients obtained were verified with Fisher's $F$ and the ANOVA test, respectively.

Finally, the inverse relation of the variables with age (age as a dependent variable) was calculated in order to attribute the age at death. Polynomial regression was calculated for both sexual series separately, but in the series without sexual differences, calculus was applied to the whole data (female and male together). This latter case enables the application of the results in archaeological and anthropological remains when the sex is unknown.

The statistical packages used were Windows SPSS/PC (Release 7.5.2S) and SAS/UNIX system (Release 6.10).

\section{Results}

The curves of sub-adults obtained by the lowess method show that the pubis length, ischiopubic index, vertical diameter and horizontal diameter of the pubis acetabular area show a very similar pattern in each sexual series (i.e. Fig. 3). However, a greater dispersion is observed in the pubis acetabular index; it being bigger within each series than between series; therefore they cannot be considered different series. On the other hand a female specimen of St. Bride collection displays a higher value 


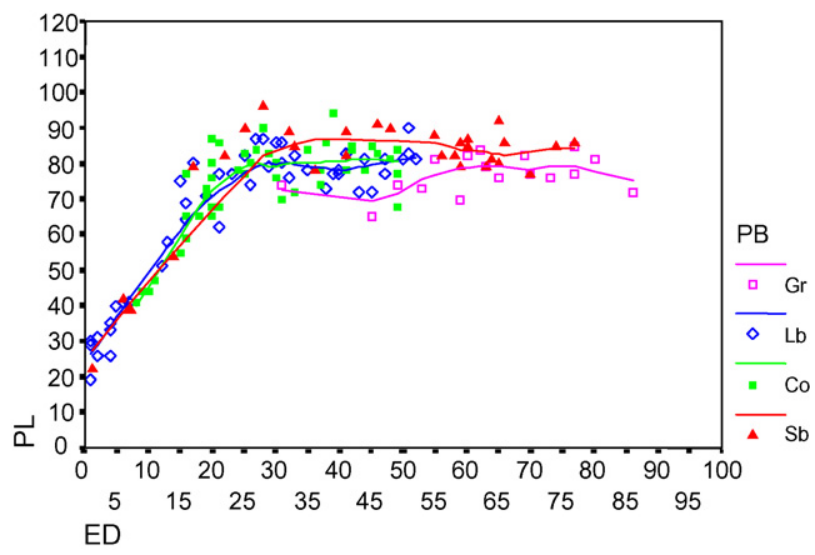

Fig. 3. Male pubis length (PL) for populations (PB). ED, age. Collections of Universitat Autònoma de Barcelona (Gr), Lisbon (Lb), Coimbra (Co) and St. Bride (Sb).

in the horizontal diameter of the pubis acetabular area. This fact distorts the results and leads to errors in the growth study of this variable. For this reason it seems advisable to remove it from the sample; this happens in ischium and ilium measurements also. Once this is done growth may be considered similar and the young specimens can be used altogether as a single population.

The tests of homogeneity of the adult populations indicate there are significant differences between the Iberian and English populations in pubis length (males: $F=7.809, p=0.000^{*}$; females: $F=13.167, p=0.000^{*}$ ) and ischium-pubic index (males: $F=5.489, \quad p=0.002^{*}$; females: $F=15.448, p=$ $\left.0.000^{*}\right)$. Therefore, these two populations have to be analyzed separately for these variables. As a consequence the number of samples is reduced and the capacity to detect the differences in the English series is affected, for this reason age categories described for adults were not considered in the English series.

For the sake of clarity, the variables will be related individually.

\subsection{Pubis length}

The female average is always bigger than the male average (Table 2). This indicates that women have a longer pubis than males from birth. However, differences are significant only from 15 to 25 years of age in the single series formed by all the younger individuals and between the adults of the English series. There are no significant differences between the two Iberian sexual series. However, the $\mathrm{p}$ value obtained was very close to being significant; because of this the sexual differences were analyzed within each Iberian series. The results obtained were the same; there were no sexual differences in the Iberian series in terms of pubis length.

The increase in growth continues until 25 years old for both males and females (Table 2). The biggest growth is between the 10-14 and 15-19 age classes, indicating the presence of the growth spurt.

The best growth model for pubis length was a fifth-degree polynomial regression in the two sexual series (Fig. 4). However, the masculine series have probabilities at the limit of significance. For this reason, other higher degree polynomial regressions in the male series were calculated, but results were worse. Only a lineal regression showed good levels of significance; but with this model most of the growth behaviour information on the male pubis length was lost. Therefore, we can conclude that growth behaviour of the pubis length is in both sexes a fifth-degree polynomial regression with an explained variability of $92 \%$ in males and $91 \%$ in females.

In the fitted curves (Fig. 4) a growth restraint is observed before the growth spurt, characteristic of the horizontal variables [23]. The beginning of the growth spurt in females is at about 10 years of age and in males is at about 14 years of age, the female growth spurt being bigger than male, in agreement with Tanner [22,24], and Gasser et at. [25].

In order to assess age at death, the inverse relation between pubis length and age was calculated (Table 3). A first-degree polynomial regression for unisex series and male series was
150

151 152 153 154 155 156 157 158 159 160 161 162 163 164 165 166 167 168 169 170 171 172 173 174 175

Table 2

Pubis length values classified according to sex and age range

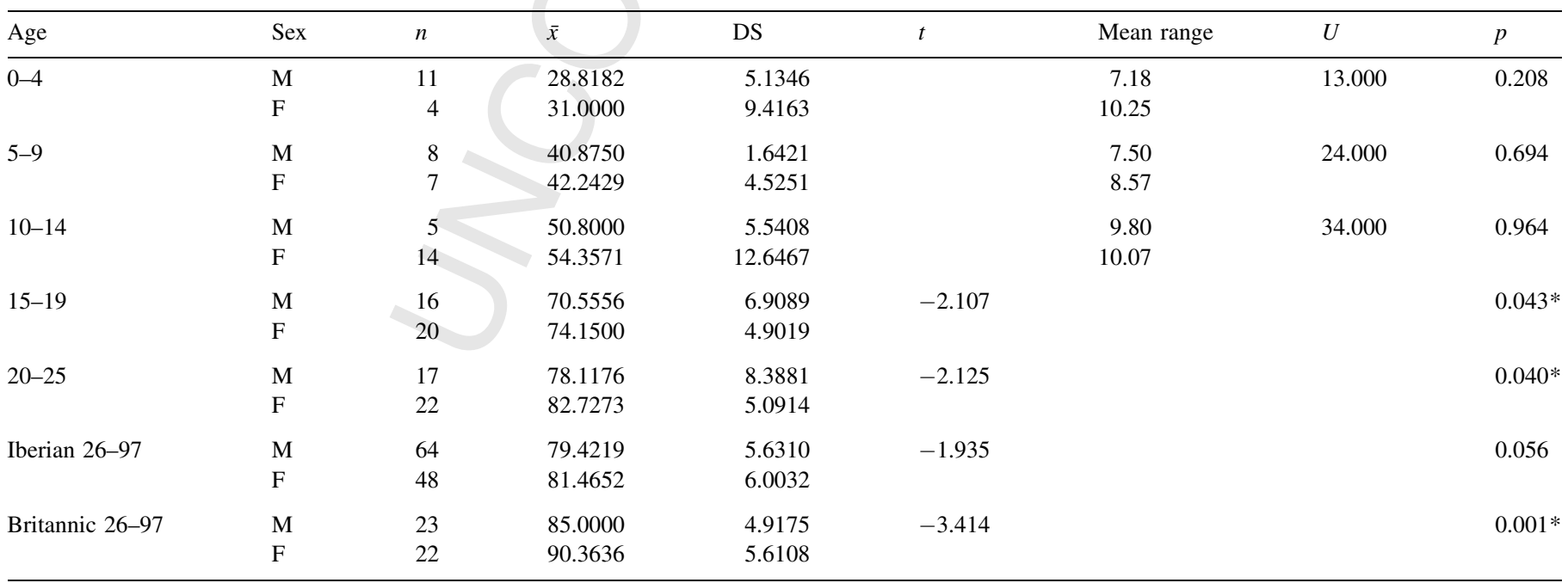

Significance values from the used test (Student's $t$-test or Mann-Whitney's $U$-test). Males are indicated by M and females are indicated by F. 

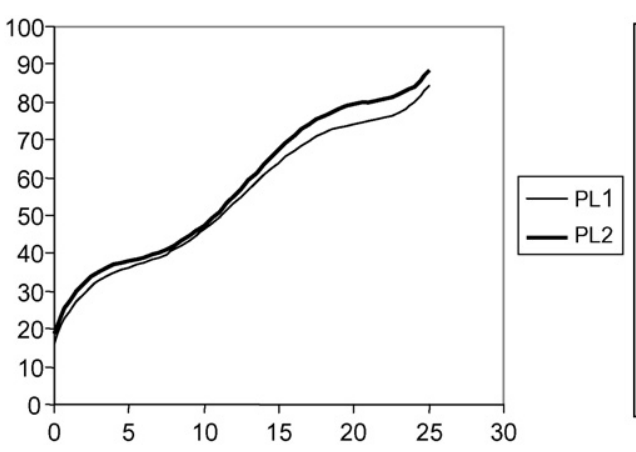

\begin{tabular}{|rrrrr|}
\hline VARIABLE & COEFICIENT & $\mathrm{t}$ & $\mathrm{p}_{1}$ & \\
Males: constant & 16.22012066 & 2.71 & $0.0091^{*}$ & $\mathrm{~F}=125.09$ \\
ed & 10.12101492 & 2,03 & $0.0471^{*}$ & $\mathrm{p}_{2}=0.0001^{*}$ \\
ed $^{2}$ & -2.10367586 & -1.76 & 0.0850 & \\
ed $^{3}$ & 0.22095646 & 1.9 & 0.0627 & $\mathrm{R}^{2}=0.9224607$ \\
ed $^{4}$ & -0.00966931 & -1.98 & 0.0531 & \\
ed $^{5}$ & 0.00014893 & 2.01 & $0.0500^{*}$ & \\
& & & & \\
Felales: constant & 18.56658362 & 3.54 & $0.0008^{*}$ & $\mathrm{~F}=130.20$ \\
ed & 10.64871958 & 2.93 & $0.0047^{*}$ & $\mathrm{p}_{2}=0.0001^{*}$ \\
ed & -2.34684624 & -2.76 & $0.0077^{*}$ & \\
ed $^{3}$ & -0.24889138 & 3.02 & $0.0037^{*}$ & $\mathrm{R}^{2}=0.914326$ \\
ed $^{4}$ & -0.01082808 & -3.10 & $0.0029^{*}$ & \\
ed $^{5}$ & 0.00016497 & 3.07 & $0.0032^{*}$ & \\
& & & & \\
\hline
\end{tabular}

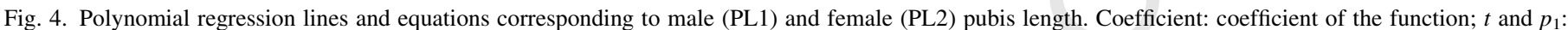
significance of the coefficient; $F$ and $p_{2}$ : significance of the functions; $R^{2}$ : explained variability.

selected with a $90 \%$ and $91 \%$ explained variability respectively. This function was prepared with individuals under 15 years of age, because sexual differences begin at this age.

In the female series it was a little difficult to attribute any polynomial regression, for this reason we tried to apply other types of non-lineal regression. The best we found was the Scurve with $92 \%$ of explained variability.

\subsection{Ischiopubic index}

In general, female averages are bigger than male, with the exception of the 5-9 age class. In this case males are $\approx 2 \mathrm{~cm}$ bigger than female (Table 4). This seems to be related to restrained growth of the feminine pubis length, which happens before the growth spurt of this area at about 6-9 years; this fact diminishes feminine ischiopubic index increment. The growth spurt of pubis length is also responsible for the big increase in the ischiopubic index in males between 15-19 and 20-25 age classes and in females between 10-14 and 15-19 age classes. The growth in this variable, like that of pubis length, continues until 25 years in both male and females.

Significant sexual differences are observed in all classes, except from 5 to 14 years old (Table 4). The increase of the feminine average between the 20-25 age class and the 26-97 age class in the English series is a consequence of the difference of the series which form both classes: 20-25 age class is mainly formed by the Portuguese series. However, these differences between Iberian and English population in adult age seem to be exclusively of the pubic length, because studies about the ilium [3] and ischium [2] elements in the same populations did not show significant differences.

Due to the slight increase observed in the ischiopubic index during the first years of life in both sexes in the present study and the approximate constancy of the ischiopubic values

Table 3

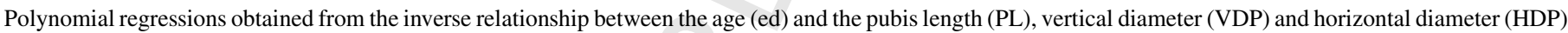
of the pubic acetabular area in archaeological (unisex series) and forensic remains (series by sex)

\begin{tabular}{|c|c|c|c|c|c|c|}
\hline & Variable & Coefficient & $p_{1}$ & $F$ & $p_{2}$ & $R^{2}$ \\
\hline \multicolumn{7}{|l|}{ Pubis length } \\
\hline $\begin{array}{l}\text { Males and females } \\
\text { ed }=0.3409 \mathrm{PL}-6.4898\end{array}$ & $\begin{array}{l}\text { PL } \\
\text { Constant }\end{array}$ & $\begin{array}{r}0.340853 \\
-6.489767\end{array}$ & $\begin{array}{l}0.0000^{*} \\
0.0000^{*}\end{array}$ & 1055.11884 & $0.0000 *$ & 0.89636 \\
\hline $\begin{array}{l}\text { Males } \\
\text { ed }=0.3633 \mathrm{PL}-7.3737\end{array}$ & $\begin{array}{l}\text { PL } \\
\text { Constant }\end{array}$ & $\begin{array}{r}0.363326 \\
-7.373717\end{array}$ & $\begin{array}{l}0.0000 * \\
0.0000 *\end{array}$ & 576.97946 & $0.0000 *$ & 0.9129 \\
\hline $\begin{array}{l}\text { Females } \\
\text { ed }=2.71828^{(4.0876-(87.3864 / P L))}\end{array}$ & $\begin{array}{l}\text { PL } \\
\text { Constant }\end{array}$ & $\begin{array}{r}-87.386412 \\
4.087610\end{array}$ & $\begin{array}{l}0.0000^{*} \\
0.0000^{*}\end{array}$ & 708.63341 & $0.0000 *$ & 0.91598 \\
\hline \multicolumn{7}{|c|}{ Vertical diameter of the acetabular area of the pubis } \\
\hline $\begin{array}{l}\text { Males and females } \\
\text { ed }=0.5794 \mathrm{VDP}-6.5995\end{array}$ & $\begin{array}{l}\text { VDP } \\
\text { Constant }\end{array}$ & $\begin{array}{r}0.579439 \\
-6.599517\end{array}$ & $\begin{array}{l}0.0000^{*} \\
0.0000^{*}\end{array}$ & 195.27540 & & 0.81271 \\
\hline $\begin{array}{l}\text { Males } \\
\text { ed = 0.611270VDP-7.367983 }\end{array}$ & $\begin{array}{l}\text { VDP } \\
\text { Constant }\end{array}$ & $\begin{array}{r}0.611270 \\
-7.367983\end{array}$ & $\begin{array}{l}0.0000 * \\
0.0000 *\end{array}$ & 236.59185 & $0.0000 *$ & 0.90443 \\
\hline $\begin{array}{l}\text { Females } \\
\text { ed }=2.71828^{(3.4647596-(36.231705 / \mathrm{VDP}))}\end{array}$ & $\begin{array}{l}\text { VDP } \\
\text { Constant }\end{array}$ & $\begin{array}{r}-36.231692 \\
3.464693\end{array}$ & $\begin{array}{l}0.0000 * \\
0.0000 *\end{array}$ & 78.46722 & $0.0000 *$ & 0.81341 \\
\hline \multicolumn{7}{|c|}{ Horitzontal diameter of the acetabular area of the pubi } \\
\hline $\begin{array}{l}\text { Males and females } \\
\text { ed }=0.8105 \mathrm{HDP}-6.5856\end{array}$ & $\begin{array}{l}\text { HDP } \\
\text { Constant }\end{array}$ & $\begin{array}{r}0.810447 \\
-6.585604\end{array}$ & $\begin{array}{l}0.0000 * \\
0.0000 *\end{array}$ & 215.11886 & & 0.82384 \\
\hline $\begin{array}{l}\text { Males } \\
\text { ed }=0.9156 \mathrm{HDP}-8.2585\end{array}$ & $\begin{array}{l}\text { HDP } \\
\text { Constant }\end{array}$ & $\begin{array}{r}0.915997 \\
-8.258501\end{array}$ & $\begin{array}{l}0.0000^{*} \\
0.0000^{*}\end{array}$ & 179.75928 & $0.0000 *$ & 0.87791 \\
\hline $\begin{array}{l}\text { Females } \\
\text { ed }=2.71828^{(3.9596-(34.5705 / \mathrm{HDP}))}\end{array}$ & $\begin{array}{l}\text { HDP } \\
\text { Constant }\end{array}$ & $\begin{array}{r}-34.570499 \\
3.959634\end{array}$ & $\begin{array}{l}0.0000 * \\
0.0000 *\end{array}$ & 166.74080 & $0.0000 *$ & 0.89771 \\
\hline
\end{tabular}

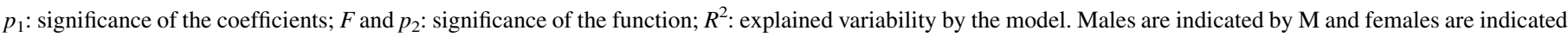
by $\mathrm{F}$. 
Table 4

Ischopubic index values classified according to sex and age range

\begin{tabular}{|c|c|c|c|c|c|c|c|c|}
\hline Age & Sex & $n$ & $\bar{x}$ & DS & $t$ & Mean range & $U$ & $p$ \\
\hline \multirow[t]{2}{*}{$0-4$} & M & 11 & 74.9370 & 5.26085 & & 6.45 & 5.000 & $0.026 *$ \\
\hline & $\mathrm{F}$ & 4 & 81.1237 & 3.28254 & & 12.25 & & \\
\hline \multirow[t]{2}{*}{$5-9$} & $\mathrm{M}$ & 8 & 77.9843 & 2.55139 & & 9.00 & 20.000 & 0.397 \\
\hline & $\mathrm{F}$ & 7 & 76.0342 & 4.04079 & & 6.86 & & \\
\hline \multirow[t]{2}{*}{$10-14$} & M & 5 & 78.1334 & 2.9995 & & 7.40 & 22.000 & 0.336 \\
\hline & $\mathrm{F}$ & 13 & 82.0750 & 6.3407 & & 10.31 & & \\
\hline \multirow[t]{2}{*}{$15-19$} & M & 16 & 81.9645 & 5.4805 & -3.608 & & & $0.001 *$ \\
\hline & $\mathrm{F}$ & 20 & 90.0659 & 7.5115 & & & & \\
\hline \multirow[t]{2}{*}{$20-25$} & $\mathrm{M}$ & 16 & 86.3743 & 9.1677 & -4.547 & & & $0.000 *$ \\
\hline & $\mathrm{F}$ & 21 & 98.8328 & 7.5006 & & & & \\
\hline \multirow[t]{2}{*}{ 26-97 Berian } & $\mathrm{M}$ & 64 & 86.2103 & 6.1228 & -10.306 & & & $0.000^{*}$ \\
\hline & $\mathrm{F}$ & 48 & 97.5743 & 5.2730 & & & & \\
\hline \multirow[t]{2}{*}{ Britannic } & M & 23 & 90.0392 & 4.4718 & -11.308 & & & $0.000 *$ \\
\hline & $\mathrm{F}$ & 22 & 106.3134 & 5.1708 & & & & \\
\hline
\end{tabular}

Significance values from the used (Student's $t$-test or Mann-Whitney $U$-test). Males are indicated by M and females are indicated by F.

observed graphically before the growth spurt, the growth before the growth spurt will be expressed as a constant. This constancy agrees with the Reynolds' results [11,12].

The growth of the ischiopubic index from 14 to 25 years old in males and from 10 to 25 years old in females can be expressed by a first-degree polynomial in both sexes (Fig. 5), but the explained variability is too low (23\% in males and $50 \%$ in females). These results indicate a large dispersion of individual values. Dispersion in index values is normal because it involves various factors [2,3,6]. Due to the low level information furnished by the models the calculus of the inverse relation between ischiopubic index and age at death has not been considered.

\subsection{Vertical diameter of the pubis acetabular area}

The feminine average is bigger than masculine before 10 years. After this age the masculine average is the biggest. There are no significant sexual differences, but in the 5-9 age class the differences are close to being significant (Table 5).

After 12 years of age, female values become stabilized due to the fusion of the coxal elements, but growth continues in boys until 16 years of age. Averages obtained for boys and girls of these ages are very different and suggest that such differences might be significant in adult stage. To corroborate this hypothesis, adult coxal bones from UAB collection were analyzed and significant differences between sexes have been found $\left(\bar{x}_{\circlearrowleft}=31.83, \bar{x}_{+}=28.64, p=0.016^{*}\right)$, indicating its utility in adult sex diagnosis.

The growth behaviour of the vertical diameter of the pubis (Fig. 6) can be expressed by a first-degree polynomial regression in males $\left(R^{2}=0.90\right)$ and a second-degree polynomial regression in females $\left(R^{2}=0.71\right)$. Models indicate a slight deceleration from the beginning in girls while boys maintain a constant growth. This fact is related with earlier feminine maturity and acetabulum size.

With regard to the inverse function for estimating age at death (Table 3), a first-degree polynomial function in unisex series $\left(R^{2}=0.81\right)$ and males series $\left(R^{2}=0.90\right)$ was obtained. In the feminine series, it was impossible to approach a polynomial regression, for this reason we tried other types of non-lineal regression and a $\mathrm{S}$-curve was the best approach $\left(R^{2}=0.81\right)$.

\subsection{Horizontal diameter of the pubic acetabular area}

Feminine and masculine averages in the horizontal diameter are similar in all age classes (Table 5). The major differences are between females belonging to the 10-12 age class and the

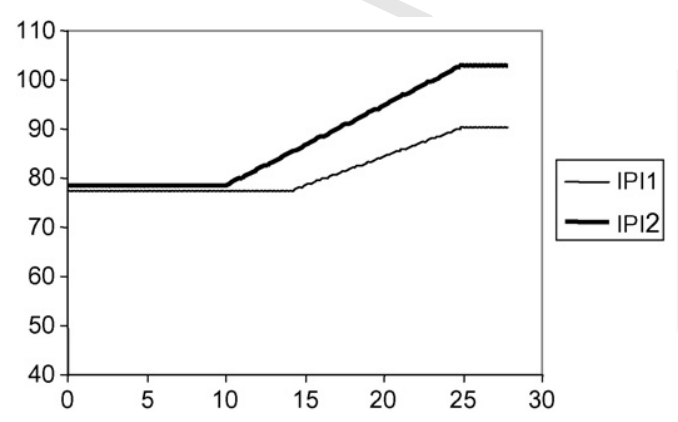

Fig. 5. Polynomial regression lines and equations corresponding to male (IPI1) and female (IPI2) ischiopubic index. Coefficient: coefficient of the function; $t$ and $p_{1}$ : significance of the coefficient; $F$ and $p_{2}$ : significance of the functions; $R^{2}$ : explained variability. 
Table 5

Vertical diameter, horizontal diameter and index of the acetabular pubic area values classified according to sex and age range

\begin{tabular}{|c|c|c|c|c|c|c|}
\hline Age & $n$ & $\bar{x}$ & DS & Mean rank & $U$ & $p$ \\
\hline \multicolumn{7}{|c|}{$\begin{array}{l}\text { Vertical diameter of the pubic acetabular area } \\
0-4\end{array}$} \\
\hline$\hat{o}$ & 11 & 16.4545 & 2.9787 & 7.18 & \multirow[t]{2}{*}{13.000} & 0.280 \\
\hline 우 & 4 & 18.0000 & 6.8799 & 10.25 & & 4 \\
\hline \multicolumn{7}{|l|}{$5-9$} \\
\hline$\hat{0}$ & 8 & 23.6250 & 1.0607 & 5.94 & \multirow[t]{2}{*}{11.500} & 0.054 \\
\hline 우 & 7 & 26.1429 & 3.7607 & 10.36 & & 7 \\
\hline \multicolumn{7}{|c|}{$10-12$} \\
\hline$\hat{0}$ & 3 & 29.0000 & 2.0000 & 8.33 & \multirow[t]{2}{*}{8.500} & 0.373 \\
\hline 우 & 9 & 27.2222 & 2.7739 & 5.89 & & 9 \\
\hline \multicolumn{7}{|c|}{$13-16$} \\
\hline$\hat{0}$ & 5 & 35.0000 & 4.1833 & - & - & - \\
\hline q & - & - & - & - & - & - \\
\hline
\end{tabular}

Horitzontal diameter of the pubic acetabular area $0-4$

$\begin{array}{lllll}\hat{3} & 11 & 11.6364 & 2.2482 & 7.45\end{array}$

$4 \quad 12.2500 \quad 3.5940 \quad 9.50$

16.000

0.489

$5-9$

$\begin{array}{lllll}\hat{0} & 8 & 17.5000 & 1.0690 & 7.94\end{array}$

$\begin{array}{lllll}\text { 우 } & 7 & 17.8571 & 2.4103 & 8.04\end{array}$

$10-12$

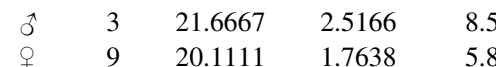

$13-16$

$\begin{array}{llll}3 & 5 & 23.0000 & 1.2247\end{array}$

Pubic acetabular index

$0-4$

$\begin{array}{rrrrr}\text { 今ิ } & 11 & 74.9370 & 5.2609 & 6.45 \\ \text { † } & 4 & 81.1237 & 3.2825 & 12.25\end{array}$

+

12.25

5-9

$\begin{array}{lll}\text { ○ิ } & 8 & 77.9843\end{array}$

q

$7 \quad 76.0342$

2.5514

4.0409

9.00

6.86

$10-12$

$\begin{array}{lll}\text { กิ } & 3 & 74.5506\end{array}$

3.7030

6.33

6.9960

6.55

$13-16$

$\begin{array}{llll}\text { ○े } & 5 & 66.4492 & 8.6982\end{array}$

Significance values from the Mann-Whitney's $U$-test. Males are indicated by $\hat{\sigma}$ and females are indicated by .

For age evaluation (Table 3 ) a first degree-polynomial in unisex $\left(R^{2}=0.82\right)$ and male $\left(R^{2}=0.88\right)$ series were obtained. In the feminine series, again it was impossible to approach the inverse function to a polynomial regression. We also tried with other types of non-lineal regression and only the S-curve showed a good approach $\left(R^{2}=0.90\right)$.

\subsection{Pubic acetabular index}

Sexual differences in pubic acetabular index during growth are basically in the first years of life, the feminine average being significantly bigger than masculine (Table 5). Pubic acetabular index diminishes in females, indicating that the vertical diameter growth is faster than the horizontal diameter. In males, pubic acetabular index first increases, and after 6-7 year old diminishes until it coincides with female values in adult age (UAB series, $\bar{x}_{\bigcirc}=60.25, \bar{x}_{+}=60.22, p=0.472$ ). This variable is therefore not useful in adult sex diagnosis; however significant differences found between 0 and 4 years of age suggest the possibility that this variable may be useful for sex diagnosis on younger age.

Growth of pubic acetabular index can be expressed by a second-degree polynomial in both sexes (Fig. 8) with $30 \%$ explained variability in males and $33 \%$ in females, indicating a large dispersion of values. It is usual to find dispersion in this index as we mention above in the ischiopubic index analysis, this is also shown in other studies $[2,3,6]$. Due to the low expressed variability and dispersion involved, we do not consider the calculus of the function to determine age at death.

\section{Discussion}

From the results of the present study, the growth pattern of the ischiopubic area can be deduced: (1) during growth before the growth spurt, the proportion between the pubis and ischium is maintained; (2) after the growth spurt, the pubis grows faster than the ischium, which increases the ischiopubic index in both sexes. However, the most significant sexual differences in the ischiopubic area are due to the feminine pubis length growth spurt. (3) The growth pattern of the acetabular area of the pubis follows an increase, which is greater in the vertical diameter of the acetabular area than the horizontal diameter, coinciding with Major [15]. However, ischium acetabular area grows faster in the vertical area than the horizontal area [2]. This is probably why the adult acetabulum is basically formed in its most part by the ischium [26].

In general curves have a good fit and there is not a great deal of scatter, as evidenced by the consistently high correlation and significance of the functions coefficients achieved in the models. The growth behaviour of pubis length is not lineal and follows a five-degree polynomial regression, displaying a nongrowth stage before the growth spurt. It coincides approximately with the results of Miles and Bulman [27], Major [15] and the obtained curves of Bruzek and Soutal [14]. This nonlineal behavior is one of the differences, which makes the distinction between the horizontal and vertical variables [23]. These differences were also observed between ischium and 


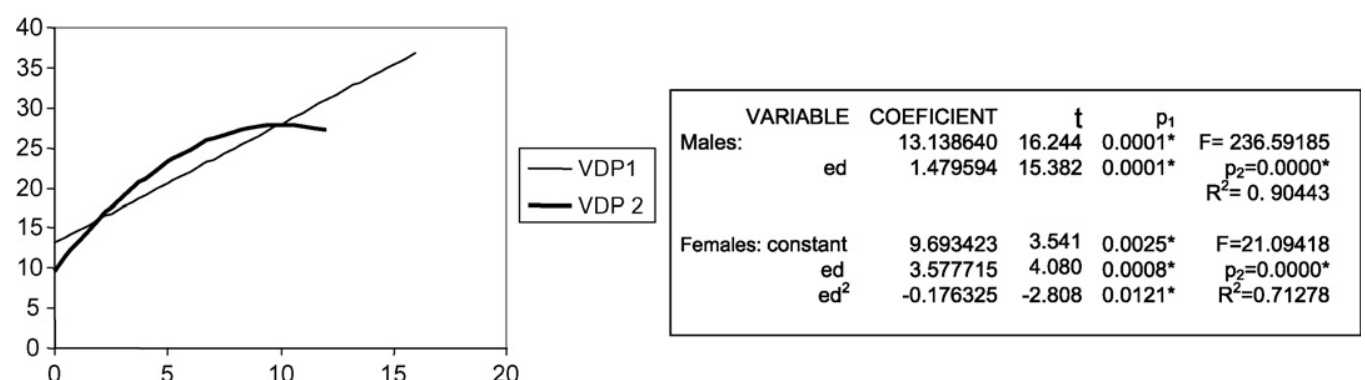

Fig. 6. Polynomial regression lines and equations corresponding to the male (VDP1) and female (VDP2) vertical diameter of the pubic acetabular area. Coefficient: coefficient of the function; $t$ and $p_{1}$ : significance of the coefficient; $F$ and $p_{2}$ : significance of the functions; $R^{2}$ : explained variability.

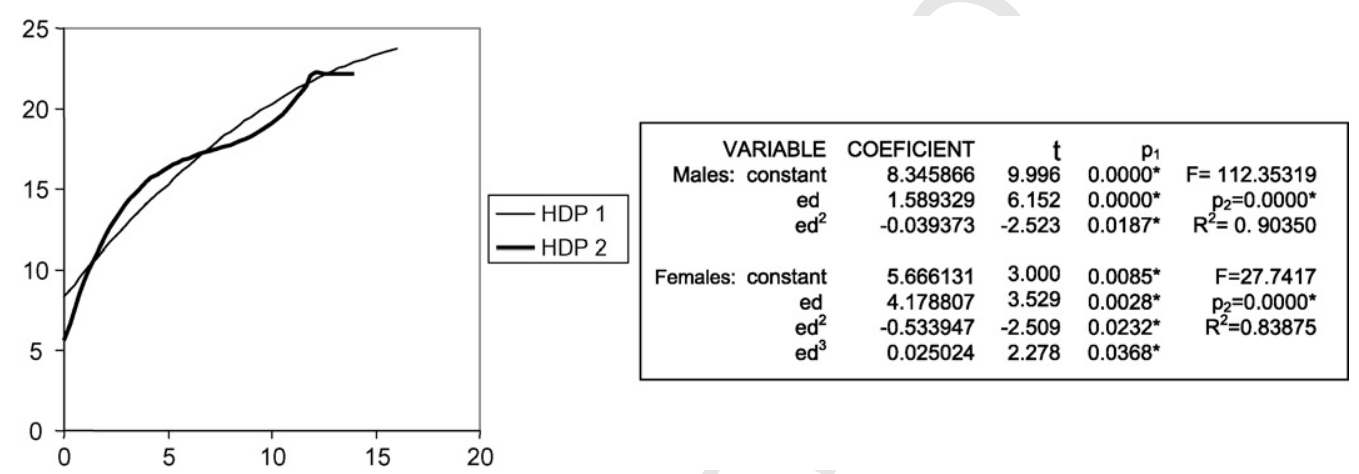

Fig. 7. Polynomial regression lines and equations corresponding to the male (HDP1) and female (HDP2) horizontal diameter of the pubic acetabular. Coefficient: coefficient of the function; $t$ and $p_{1}$ : significance of the coefficient; $F$ and $p_{2}$ : significance of the functions; $R^{2}$ : explained variability.

ilium length (vertical variables) and the ilium width (horizontal variable) in Rissech et al. [2] and, Rissech and Malgosa [3], respectively. Data from the other measurements of the juvenile acetabulum proposed in this study are not available from other studies, but they are similar to the acetabular area of the ischium [2] and ilium [3]. It has been observed that the growth of the acetabular area measurements is well described as first or second degree polynomial regression; they do not display the growth spurt. This is caused by the fusing of the acetabulum before the age at which the growth spurt occurs.

Pubis length and ischiopubic index are the only variables having an indicator of the growth spurt. In the case of pubis length, it is the upturn of the curve, and in the ischiopubic index it is the start of the growth of this variable. Both pubis length and ischiopubic index indicate that the growth spurt in the pubis is at about 10 years of age in females and 14 years of age in males. This occurs earlier than in the ilium, which takes place before 11 and 15 years of age in females and in males respectively [4], coinciding with the opinion of Major [15].

The ages of the growth spurt found in the ischiopubic area (pubis and ischiopubic index) in the present study fall into the standard intervals of age for puberal growth spurt in the existing population: 10.5-17.5 years of age in males and 9.5-14.5 in females [16]. On the other hand, the mean age of fusion of the acetabulum (acetabulum maturity) is 16 in males and 12 in females, which also falls into the standard intervals for the current population: $14-17$ and $11-15$ in males and females respectively [28]. Both characteristics indicate no delay in growth in our series. In general it is possible to say that the ischiopubic area of the series analyzed does not show evidence of secular change, malnutrition, nor delay in growth or osseous maturation. The observed differences in the pubic area are

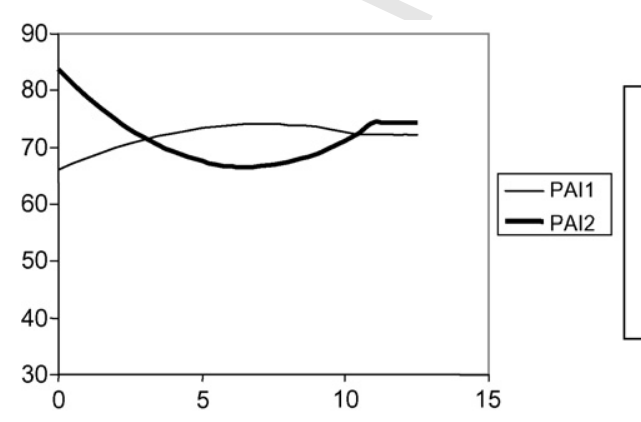

\begin{tabular}{|rrrrr|}
\hline VARIABLE & COEFICIENT & $\mathrm{t}$ & $\mathrm{p}_{1}$ & \\
Males: constant & 65.957688 & 20.748 & $0.0000^{*}$ & $\mathrm{~F}=4.10181$ \\
ed & 2.268317 & 2.241 & $0.0371^{*}$ & $\mathrm{p}_{2}=0.0331^{*}$ \\
ed $^{2}$ & -0.158877 & -2.604 & $0.0174^{*}$ & $\mathrm{R}^{2}=0.30156$ \\
& & & & \\
Females: constant & 83.858318 & 13.933 & $0.0000^{*}$ & $\mathrm{~F}=4.2343$ \\
ed & -5.247877 & -2.722 & $0.0145^{*}$ & $\mathrm{p}_{2}=0.0329^{*}$ \\
ed $^{2}$ & 0.397426 & 2.879 & $0.0104^{*}$ & $\mathrm{R}^{2}=0.32089$ \\
& & & & \\
\hline
\end{tabular}

Fig. 8. Polynomial regression lines and equations corresponding to the male (PAI1) and female (PAI2) pubic acetabular index. Coefficient: coefficient of the function; $t$ and $p_{1}$ : significance of the coefficient; $F$ and $p_{2}$ : significance of the functions; $R^{2}$ : explained variability. 
exclusively focused in pubis length (absolute and relative variables), mainly between English and Iberian females, and Spanish and English males (see Rissech [29]). These observed differences seem to be related to the body size of the three different populations, Portuguese, Spanish and English, having the later biggest body size. In fact, Maclaughlin and Bruce [30] and Moerman [31] found a complex relationship between the pubis length and the body size, specifically with the stature; this relationship was different in both sexes and in the different populations. On the other hand, it is St. Bride, the oldest series, that shows bigger values of the pubis length. Therefore differences could be probably constitutional and not related with secular change.

The results obtained related to the age growth stop in pubis length coincide with the results of the feminine series studied by Tague [32] and disagree with Fuller [33]. According to Fuller the results obtained by Tague are due to a possible retarded maturation of the series used, which were a prehistoric American series. However, our study showed continuing growth of the pubis and the ischiopubic index until 25 years of age in both sexes. Furthermore, our series corresponds to a contemporary European series, whose growth spurt age and acetabular maturation coincides with that of the current population. As we say in the study of the ischium [2], the age that growth stature ceased was fixed for practical reasons $[16,34]$ and shows the end of most notable growth, certain segments continue growing [22]. These results agree with the opinion that the innominate ceases its growth later than the long bones [35,36].

Sexual dimorphism. From our results, the high rate of feminine growth spurt is at the beginning of sexual differences in adult pubis length, which is characteristic of the horizontal variables [36]. The sexual differences in ischiopubic index are also due to the high rate of the feminine growth spurt, but its differences are amplified by the early end of growth at 20 years of age in female ischium length, while masculine ischium length continues growing until 25 years [2]. The statistical significance of the adult sexual differences in the ischiopubic index agrees with the accepted importance of this variable in sexual determination. Adult pubis length results agree with Genovés [6], Thieme and Schull [7] and Arsuaga [9] in which women have a longer pubis than males. In our study, however, the differences have significance only in the English series and not in the Iberian series. In this case, the lack of significance cannot be attributed to the size of the sample; we believe that it can be a consequence of the complex relationship of pubis length with sex and the corporal size of the population. As we said before, pubis length is related to stature [31] and this relation varies in accordance with the population [30,37]. For this reason, adult pubis length considered independently in sexual diagnosis has low significance [37-39].

Therefore, the ischiopubic index, pubis length and the two absolute variables of the pubic acetabular area of the pubis are useful for adult sex determination. The ischiopubic index and pubis length are effective from 15 years of age, the vertical and horizontal variables of the pubic acetabular area are effective from 12 years. However, the Ischopubic index and the two variables of the pubic acetabular area are the most effective adult sex predictors.

There are few works that analyze the infantile ischiopubic area from bone remains [14,15,27]. In spite of analyzing infantile pubic and ischium growth, they only analyze the sexual differences of the ischiopubic index. However, some studies on radiographic material have stated that female pubis length was larger than that of males in all ages $[11,12,13]$. This difference was significant between 3.75 and 5.75 years [11,12] and between 9 and 18 years [13]. In the present study, the significant differences are observed between 15 and 25 years in the single series formed by all the younger individuals but, the major/minor relation is the same.

In general, the ischiopubic index results from our study coincide with the results of Major [15] and Bruzek and Soustal [14]. Major found significant sexual differences during the first years of life and Bruzek and Soustal from 10 years old. On the other hand, the observed constancy of the averages between the first ten years of age in the present study and the obtained values of the ischiopubic index from Reynolds study [11,12] indicate the importance of the ischiopubic index in sub-adult sex determination.

In spite of the small number of our samples and of the caution needed, vertical diameter of the pubic acetabular area and the pubic acetabular index seem useful for sub-adult sexual diagnosis. These results agree with Reynolds [11] who found sexual dimorphism for the ilium-ischium cartilage during the first year of life. These results also agree with the results obtained before for the ischium [2] and the ilium [3] acetabular area and indicate the usefulness of the acetabulum for sub-adult sex diagnosis.

The results of the present work strongly indicate the importance of the acetabulum and the ischiopubic index in adult sex prediction and probably in sub-adults. On the other hand, they diminish the importance of the pubis.

Age determination. It is possible to estimate age at death of sub-adult individuals by using the absolute measurements of the pubis. The application of the regression equation for pubis length is of greatest use because it does not become stable until 25 years of age in both males and females. Measurements of the acetabular area have the most reduced application time, because acetabular fusion occurs early on in development; vertical and horizontal diameters are applicable only before 12 year of age in females and 16 years of age in males.

The regression formulae calculated from the recent Western European populations analyzed in this study allow us to predict the age of young human remains with accuracy. In general, calculated curves fit well with our mixed European series and correspond with the behaviour deduced from the adult bone and other skeletal segments.

\section{Conclusion}

The cross-sectional study of the pubic growth based on four documented skeletal series from Western Europe has enabled formulae calculus to obtain a valuable age diagnosis of the subadult skeleton from pubis length and two new variables of the 
pubic acetabular area, vertical diameter and horizontal diameter. It has also provided us with information about the sub-adult and adult sexual dimorphism of the pubic area, indicating the possible importance of the ischiopubic index in sub-adult sexual diagnostic in most ages and the pubic acetabular index during the first years of life. Results also reinforce the importance of the ischiopubic index and the importance of the acetabulum in adult sexual diagnostic, specifically suggesting the importance of two new variables described in the present study of the pubic acetabular area.

The formulae are the first formulae obtained from the pubic area to diagnose osseous age in Western European human remains, taking into account the fact that they cross the limits of innominate fusion. These results and formulae obtained from pubis area for sex and age diagnosis provided us with an important tool for anthropological and forensic tasks. However, further research on growth and development of the skeletal elements is necessary in order to obtain better information for skeletal diagnosis, specifically in sub-adults.

\section{Acknowledgements}

This work was partially funded by BOS2002-00719 MEC Spanish project.

We are grateful to Canon John Oates, Professor L. Scheuer, Professor S. Black, Professor E. Cunha, Professor $\mathrm{M}^{\mathrm{a}}$ Rocha, Professor Director C. Almaça, Mr. L. Lopes and Professor G. Ramalhinho for access to human skeletal collections.

\section{References}

[1] C. Rissech, J.R. Sañudo, A. Malgosa, The acetabular point: a morphological and ontogenetic study, J. Anat. 198 (2001) 743-748.

[2] C. Rissech, M.M. García, A. Malgosa, Sex and age diagnosis by ischium morphometric analysis, For. Sci. Int. 135 (2003) 188-196.

[3] C. Rissech, A. Malgosa, Ilium growth study: applicability in sex and age diagnosis, For. Sci. Int. 147 (2005) 165-174.

[4] T.W. Todd, Age changes in the pubic bone: the male white pubis, Am. J. Phys. Anthropol. 3 (1921) 285-339.

[5] A.H. Schultz, The skeleton of the trunk and limbs of higher primates, Hum. Biol. 2 (1930) 303-438.

[6] S. Genovés, Diferencias sexuales en el hueso coxal, Universidad Nacional Autónoma de México, Publicaciones del Instituto de Historia, Mexico, México, 1959

[7] F.P. Thieme, W.J. Schull, Sex determination from the skeleton, Hum. Biol. 29 (1957) 242-273.

[8] V. Novotny, Sex differences of pelvis and sex determination in paleoanthropology, Antropology XXI/1 (1983) 65-72.

[9] J.L. Arsuaga, Antropología del hueso coxal: evolución, dimorfismo sexual y variabilidad, PhD dissertation, Universidad Complutense de Madrid, 1990.

[10] S. Brooks, J.M. Suchey, Skeletal age determination based on the os pubis: a comparison of the Ascádi-Nemeskeri and Suchey-Brooks methods, Hum. Evol. 5 (3) (1990) 227-238.

[11] E.L. Reynolds, The bony pelvic gridle in early infancy. A roentgenometric study, Am. J. Phys. Anthropol. 3 (1945) 321-354.

[12] E.L. Reynolds, The bony pelvis in prepuberal childhood, Am. J. Phys Anthropol. 5 (1947) 165-200.

[13] W.H. Coleman, Sex differences in the growth of the human bony pelvis, Am. J. Phys. Anthropol. 31 (1969) 125-152.
[14] J. Bruzek, K. Soustal, Contribution to ontogenesis of human bony pelvis, Acta Univ. Carolinae-Biologica 12 (1984) 37-45.

[15] T. Majó, L'os coxal non-adulte: approche méthodologique de la croissance et de la diagnose sexuelle. Appication aux enfants du paléolithique moyen, $\mathrm{PhD}$ dissertation, Université Bordeaux 1, 2000.

[16] S.M. Black, J.L. Scheuer, The ontogenetic development of the cervical rib, Int. J. Osteoarchaeol. 7 (1997) 2-10.

[17] S.M. Black, J.L. Scheuer, Age changes in the human clavicle: from the early neonatal period to skeletal maturity, Int. J. Osteoarchaeol. 6 (1996) 425-434.

[18] S.M. Black, J.L. Scheuer, Occipitalisation of the atlas with reference to its embryological development, Int. J. Osteoarchaeol. 6 (1996) 189-194.

[19] S. Safont, A. Malgosa, E. Subira, Sex assessment on the basis of long bone circumference, Am. J. Phys. Anthropol. 113 (2000) 317-328.

[20] M.A. Rocha, Les collections ostéologiques humaines identifiées du Musseé Anthropologique de l'Université de Coimbra, Antropologia Portuguesa 13 (1995) 17-38.

[21] H. Cardoso Hugo, Brief communication: the collection of identified human skeletons housed at the Bocage Museum (National Museum of Natural History), Lisbon, Portugal, Am. J. Phys. Anthropol. 129 (2006) 173-176.

[22] J.M. Tanner, Growth at Adolescence, 2nd ed., Blackwell Scientific Publications, Oxford, 1962

[23] F. Twiesselmann, Développement biomètrique de l'enfant á l'adulte, Presses Universitaires de Bruxelles-Librairie Maloine, Paris, 1969.

[24] J.M. Tanner, El hombre antes del hombre, Fondo de cultura economica, Mexico, 1986.

[25] T. Gasser, A. Kneip, P. Ziegler, R. Largo, L. Molinari, A. Prader, The dynamics of growth of width in distance, velocity and acceleration, Ann. Hum. Biol. 18 (1991) 449-461.

[26] L. Aiello, C. Dean, An Introduction to Human Evolutionary Anatomy, Academic Press Limited, London, 1990.

[27] A.E. Miles, J.S. Bulman, Growth curves of immature bones from a Scottish island population of sixteenth to mid-nineteenth century: shoulder, girdle, ilium, pubis and ischium, Int. J. Osteoarchaeol. 5 (1995) 15-27.

[28] L. Scheuer, S. Black, Developmental Juvenile Osteology, Academic Press, London, 2000

[29] C. Rissech, Anàlisis del creixement del coxal a partir de material ossi i les seves aplicacions en la MedicForense i l'Antropologia, PhD dissertation, Universitat Autònoma de Barcelona, 2001

[30] S.M. Maclaughlin, M.F. Bruce, Population variation in sexual dimorphism in the human innominate, Hum. Evol. 1 (3) (1986) 221-231.

[31] M.L. Moerman, A longitudinal study of growth in relation to the body size and sexual dimorphism in the pelvis, $\mathrm{PhD}$ dissertation, University of Michigan.

[32] R.G. Tague, Maternal mortality or prolonged growth: age at death and pelvic size in three prehistoric Amerindian populations, Am. J. Phys. Anthropol. 95 (1994) 27-40.

[33] K. Fuller, Adult females and pubic bone growth, Am. J. Phys. Anthropol. 106 (1998) 323-328.

[34] A.F. Roche, G.H. Avila, Late adolescent growth in stature, Pediatrics 50 (1972) 874-880.

[35] L.T. Humhrey, Growth patterns in the modern human skeleton, Am. J. Phys. Anthropol. 105 (1998) 57-72.

[36] J.M. Tanner, R.H. Whitehouse, E. Marubini, L.F. Resele, The adolescent growth spurt of boys and girls of the Harpenden Growth Study, Ann. Hum. Biol. 3 (2) (1976) 109-126.

[37] M.L. Patriquin, M.S. Steyn, S.R. Loth, Metric analysis of sex differences in South African black and white pelves, For. Sci. Int. 147 (2004) 117119.

[38] C. Rissech, A. Malgosa, Importancia relativa de la longitud del pubis y la anchura del ilion en el estudio del dimorfismo sexual de los coxales, Bol. Soc. Esp. Antrop. Biol. 12 (1991) 29-43.

[39] C. Rissech, A. Malgosa, Sex prediction by discriminant function with central portion measures of innominate bones, Homo 48 (1) (1997) 22-32. 